\title{
Discovery of 1,4-Didydroxy-2-naphthoate Prenyltransferase
}

\section{Inhibitors:}

\author{
New Drug Leads for Multidrug-Resistant Gram-Positive Pathogens \\ Michio Kurosu* , Prabagaran Narayanasamy, Kallolmay Biswas, Rakesh Dhiman, and Dean \\ C. Crick \\ Department of Microbiology, Immunology, and Pathology, College of Veterinary Medicine and \\ Biomedical Sciences, Colorado State University, 1682 Campus Delivery, Fort Collins, Colorado \\ 80523-1682
}

\begin{abstract}
Since utilization of menaquinone in the electron transport system is a characteristic of Gram-positive organisms, the 1,4-dihydroxy-2-naphthoate prenyltransferase (MenA) inhibitors 1a and 2a act as selective antibacterial agents against organisms such as methicillin-resistant Stapylococcus aureus (MRSA), Staphylococcus epidermidis (MRSE), and Mycobacterium spp. Growth of drug-resistant Gram-positive organisms was sensitive to the MenA inhibitors, indicating that menaquinone synthesis is a valid new drug target in Gram-positive organisms.
\end{abstract}

Antimicrobial resistance of pathogens is a global problem. Each year worldwide, more than 11 million people die from the major infectious killers (i.e., MDR ${ }^{\mathrm{a}}$ tuberculosis, malaria, HIV, diarrhea diseases, and pneumonia). ${ }^{1}$ The increasing drug resistance among Gram-positive bacteria is a significant problem because they are responsible for one-third of nosocomial

\footnotetext{
a Abbreviations:

MenA

1,4-dihydroxy-2-naphthoate prenyltransferase

MDR

multidrug-resistant

MRSA

methicillin-resistant Stapylococcus aureus

MRSE

methicillin-resistant Staphylococcus epidermidis

Mtb

Mycobacterium tuberculosis

CoQ

ubiquinone

DHNA

1,4-dihydroxy-2-napthoate

DMMK

*To whom correspondence should be addressed. For M.K.: phone, 970-491-7628; fax, 970-491-1815; e-mail, michio.kurosu@colostate.edu. For D.C.C.: phone, 970-491-3308; fax, 970-491-1815; e-mail, dean.crick@ colostate.edu.

Supporting Information Available: Experimental procedures and results from characterization of compounds and MenA inhibitory assay. This material is available free of charge via the Internet at http://pubs.acs.org. 
infections; drug resistance in Gram-positive organisms (i.e., staphylococci, pneumococci, vancomycin resistance in enterococci, and mycobacteria) have achieved prominence in the past 15 years. Methicillin-resistant $S$. aureus (MRSA) is one of most frequent nosocomial pathogens in developed countries. ${ }^{2}$ In addition, Mycobacterium tuberculosis (Mtb) is responsible for nearly 2 million deaths annually and one-third of the world population is infected with latent Mtb. In particular, people who are malnourished or have HIV-AIDS are susceptible to TB infection. Moreover, the emergence multidrug-resistant strains of Mtb (MDR-TB) seriously threatens TB control and prevention efforts. ${ }^{3}$ The results of over 10 years of screening of strains and molecular targets (existing and new) from traditional product sources (randomly generated library molecules, secondary metabolites, and drug libraries) have been disappointing. ${ }^{4}$ Therefore, identification of new molecular targets and mechanisms of action that involved identifying essential, ubiquitous bacterial genes in pathogens that are prokaryote and eukaryote selective to prevent side effects in the host has been studied.

The lipid-soluble electron carriers (lipoquinones) occupy a central and essential role in electron transport coupled ATP synthesis. The lipoquinones involved in the respiratory chains of bacteria consist of menaquinones and ubiquinones. From the taxonomic studies it is evident that a majority of Gram-positive bacteria including Mycobacterium spp. utilize only menaquinone in their electron transport systems,, 5 and menaquinone biosynthesis is essential for survival of nonfermenting Gram-positive bacteria. ${ }^{6}$ On the other hand, Gram-negative organisms such as $E$. coli utilize ubiquinone $(\mathrm{CoQ})$ under aerobic conditions and utilize menaquinone under anaerobic conditions. Moreover, the electron transport chain in humans does not utilize menaquinone. ${ }^{7}$ Therefore, inhibitors of menaquinone biosynthesis have great potential for the development of novel and selective drugs against MDR Gram-positive pathogens. ${ }^{8}$ However, no study on the development of inhibitors for menaquinone biosynthetic enzymes has been reported. In this communication, we report that inhibition of 1,4dihydroxy-2-naphthoate prenyltransferase (MenA), which catalyzes a formal decarboxylative prenylation of 1,4-dihydroxy-2-napthoate (DHNA) (Figure 1), ${ }^{9}$ showed significant growth inhibitory activities against drug-resistant Gram-positive bacteria.

The MenA activity was characterized using membrane fractions prepared from $M$. tuberculosis as previously described. ${ }^{11}$ MenA is predicted to have five transmembrane segments, and there are highly conserved Asp residues that would be located in the innerplasma membrane. ${ }^{12}$ The activity is absolutely dependent on the presence of the divalent cations such as $\mathrm{Mg}^{2+}$. Thus, it is likely that such divalent cations form ion pairs with Asp residues existing in the catalytic site of MenA. On the basis of the observation of this enzymatic activity and the structure of the MenA product, demethylmenaquinone (DMMK), we designed tertiary or secondary amine or hydrazine-containing DMMK mimics (1) in hope that the amine moiety would interact with Asp residue(s) directly or through the divalent cation(s) in the active site and (2) in which the chemically unstable 1,4-quinone system is replaced with the hydrophobicly substituted benzophenones. As illustrated in Scheme 1, the designed DMMK mimics were synthesized efficiently in four to six steps including (1) Friedel-Crafts acylation, (2) deprotection, (3) alkylation(s), (4) bromination, and (5) amination reactions.

We have synthesized 100 molecules in solution, and the library of molecules was evaluated in enzymatic assays in vitro $\left(\mathrm{IC}_{50}\right)$ against Mtb MenA ${ }^{11}$ and in mycobacterial growth assays (MIC). More than 18 molecules exhibited MenA $\mathrm{IC}_{50}$ and MIC values of less than $20 \mu \mathrm{M}$, and in all cases the MIC value was in good agreement with the $\mathrm{IC}_{50}$ value. From these preliminary screenings it was shown that the shorter length of linker (C5-C7 in 1) between the phenolic oxygen and the nitrogen atom decreased the ability to inhibit MenA and the efficacy of growth inhibition. In addition, the structure of amine or hydrazine significantly influences the activity; $\alpha$-substituted amine or bulky tertiary amine containing molecules did not show MenA inhibitory activity at lower concentrations. ${ }^{10}$ Identification of the effective substitution pattern 
$\left(\mathrm{R}_{1}, \mathrm{R}_{2}, \mathrm{R}_{3}\right.$, and $\left.\mathrm{R}_{4}\right)$ in benzophenone moiety requires extensive SAR studies; however, the hydroxy group on $\mathrm{R}_{3}\left(\mathrm{R}_{3}=\mathrm{OH}\right.$ in $\mathbf{1}$ and $\left.\mathbf{3}\right)$ seems to be superior to the others $\left(\mathrm{R}_{3}=\mathrm{H}\right.$ or $\left.\mathrm{Cl}\right)$ regardless of the structure of linker. ${ }^{13}$

Two molecules 1a and 2a, named allylaminomethanone-A and phenethylaminomethanone-A, respectively, showed MIC values of 1.5 and $12.5 \mu \mathrm{g} / \mathrm{mL}$ against Mtb (H37Rv, a common laboratory strain), respectively. We resynthesized 1a and $\mathbf{2 a}$ and determined MICs $(\mu \mathrm{g} / \mathrm{mL})$ against a variety of species and strains of Gram-positive (entries 1-19 in Table 1) and Gramnegative bacteria (entries 20-23 in Table 1). As summarized in Table 1, only Gram-positive bacterial growth was inhibited by $\mathbf{1 a}$ (for Mtb) and $\mathbf{2 a}$ (others), supporting the hypothesis that menaquinone synthesis is the target of these molecules. ${ }^{14}$ In addition, growth of drug-resistant Gram-positive organisms was sensitive to the MenA inhibitors (entries 2, 3, 14, 10-17), indicating that MenA is likely to be a valid drug target in Gram-positive pathogens involved in emerging diseases.

In conclusion, we have shown, for the first time, that MenA inhibitors 1a and 2a inhibited growth of drug-resistant Mycobacterium spp. and other Gram-positive bacteria at low concentrations. The MenA inhibitors described here can be synthesized cost-effectively, and structural modifications to improve the inhibitory activity in vitro can be achieved in a time efficient manner. The results are expected to be of significance in terms of discovering new lead molecules that can be developed into new drugs to combat Gram-positive pathogens.

\section{Acknowledgment}

This paper is dedicated to Professor Yoshito Kishi (Harvard University) on the occasion of his 70th birthday. We thank the National Institutes of Health (NIAID Grants AI049151, AI018357, and AI06357) for generous financial support. We are grateful to Drs. Yamada and Hanaki (Kitasato Institute Research Center) and Dr. Matsumoto (Otsuka Pharmaceutical) for conducting MIC assays.

\section{References}

(1). Grenet K, Guillemot D, Jarlier V, Moreau B, Dubourdieu S, Ruimy R, Armand-Lefevre L, Brau P, Andremont A. Antibacterial resistance, Wayampis Amerindians, French Guyana. Emerging Infect. Dis 2004;10:1150. [PubMed: 15207074]

(2)(a). Gaynes R, Edwards JR. Overview of nosocomial infections caused by Gram-negative bacilli. Healthcare Epideol 2005;41:848-854. (b) Francis JS, Doherty MC, Lopatin U, Johnston CP, Sinha G, Ross T, Cai M, Hanse NN, Per T, Ticehurst JR, Carroll K, Thomas DL, Nuermberger E, Bartlett JG. Severe community-onset pneumonia in healthy adults caused by methicillin-resistant Staphylococcus aureus. Clini. Infect. Dis 2005;40:100-1007. (c) Schroeder MS. Clostridium difficile-associated diarrhea. Am. Fam. Physician 2005;71:921. [PubMed: 15768622] (d) Haddadin AS, Fappiano SA, Lipsett PA. Methicillin resistant Staphylococcus aureus (MRSA) in the intensive care unit. Postgrad. Med. J 2002;78:385-392. [PubMed: 12151652] (e) Richards MJ, Edwards JR, Culver DH, Gaynes RP. Nosocomial infections in medical intensive care units in the United States. Crit. Care Med 1999;27:887-892. [PubMed: 10362409] (f) Martin MA. Methicillin-resistant Staphylococcus aureus: the persistent resistant nosocomial pathogen. Curr. Clin. Top. Infect. Dis 1994;14:170-191. [PubMed: 8086114]

(3). Cohen J. New TB drug promises shorter, simpler treatment. Science 2004;306:1872. [PubMed: 15591168]

(4). Pagune DJ, Gwynn MN, Holmes DJ, Pompliano DL. Drugs for bad bugs: confronting the challenges of antibacterial discovery. Nat. Rev 2007;6:29-40.

(5). The peptide sequences of the menA and $u b i A$ gene products were only $21 \%$ identity and $35 \%$ similarity. See the following:Suvana KD, Stevenson R, Meganathan R, Hudspeth MES. Menaquinone (vitamin K2) biosynthesis: localization and characterization of the menA Gene from Escherichia coli. J. Bacteriol 1998;180:2782-2787. [PubMed: 9573170] 
(6)(a). Bentley R. Biosynthesis of vitamin-K and other natural naphthoquinones. Pure Appl. Chem 1975;41:47-68. (b) Bentley R, Meganathan R. Biosynthesis of vitamin K (menaquinone) in bacteria. Microbiol. Rev 1982;46:241-280. [PubMed: 6127606] (c) Martin JL, McMillan FM. SAM (dependent) I AM: the $S$-adenosylmethionine-dependent methyltransferase fold. Curr. Opin. Struct. Biol 2002;12:783-793. [PubMed: 12504684]

(7)(a). Truglio JJ, Theis K, Feng Y, Gajda R, Machutta C, Tong PJ, Kisher C. Crystal structure of Mycobacterium tuberculosis $\mathrm{MenB}$, a key enzyme in vitamin $\mathrm{K}_{2}$ biosynthesis. J. Biol. Chem 2003;24:42352-42360. [PubMed: 12909628] (b) Collins MD, Jones D. Distribution of isoprenoid quinone structural types in bacterial and their taxomic implication. Microbiol. Rev 1981;45:316354. [PubMed: 7022156] (c) Bishop DHL, Pandya KP, King HK. Ubiquinone and vitamin K in bacteria. Biochem. J 1962;83:606-614. [PubMed: 13869492]

(8). Clearly, the electron transport chain is a central component in the production of ATP and the subsequent growth of bacteria.

(9). MenA is a membrane-associated protein, and so far no crystal structure has been reported. Detailed mechanism of biosynthesis of DMMK catalyzed by MenA has not been reported.

(10). For details, see Supporting Information.

(11). Mtb utilizes nonaprenyldiphosphate ( $n=8$ in Figure 1 ) as an electrophile for DHNA in the synthesis of menaquinone. Conveniently, it was observed that farnesyl-PP (FPP) can be utilized as a substrate and we utilized $\left[{ }^{3} \mathrm{H}\right]$-labeled FPP for MenA inhibitory assays. ${ }^{9}$ For localization and characterization of the menA gene from E. coli, see the following:Shineberg B, Young IG. Biosynthesis of bacterial menaquinones: the membrane-associated 1,4-dihydroxy-2-naphthoate octaprenyltransferase of Escherichia coli. Biochemistry 1976;15:2754-2758. [PubMed: 949474]

(12). Hirokawa T, Boon-Chieng S, Mitaku S. Classification and secondary structure prediction system for membrane proteins. Bio-informatics 1998;14:378-379.

(13). Generation of small optimized libraries based on 1a and 2a is in progress.

(14). The difference in sensitivities of $\mathbf{2} \mathbf{a}$ against Mycobacterium spp. is probably due to the compositional complexity of the mycobacterial cell envelope, which differentiates their drug sensitivity from that of most other prokaryotes. On the other hand, 1a may show lower permeability of the other Grampositive cell wall than $\mathbf{2 a}$. 

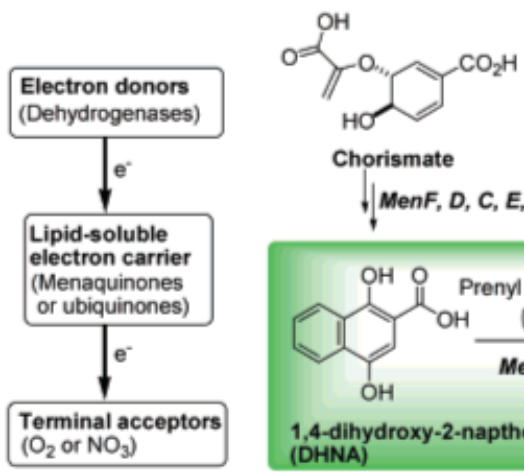

Chorismate

MenF, D, C, E, and B

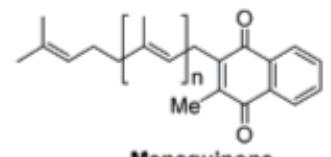

Menaquinone

MenG

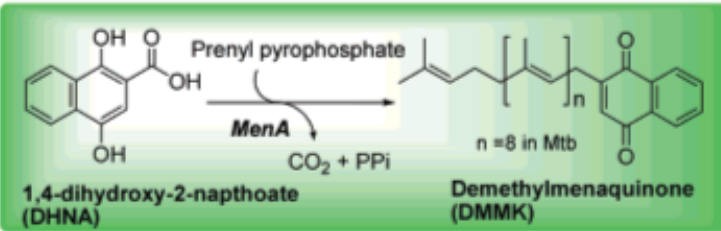

$\begin{array}{ll}\text { 1,4-dihydroxy-2-napthoate } & \text { Demethylm } \\ \text { (DHNA) } & \text { (DMMK) }\end{array}$

Figure 1.

Schematic bacterial electron transport chain and menaquinone biosynthesis. 


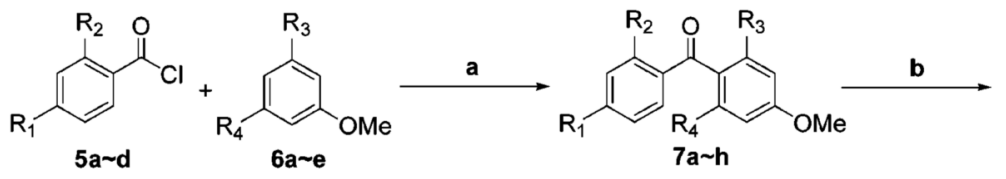

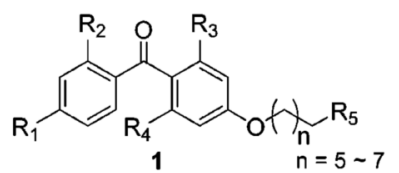<smiles>[R3]CCCOC/C=C/COc1cc([R3])c(C(=O)c2ccc([R])cc2[R])c([R3])c1</smiles><smiles>[R5]CCCO[14CH2]Oc1cc([R3])c(C(=O)c2ccc([R])cc2[R2])c([R3])c1</smiles><smiles>[R6]CCCOCC#CCOc1cc([R3])c(C(=O)c2ccc([R])cc2[R2])c([R3])c1</smiles><smiles>[R7][B]</smiles>

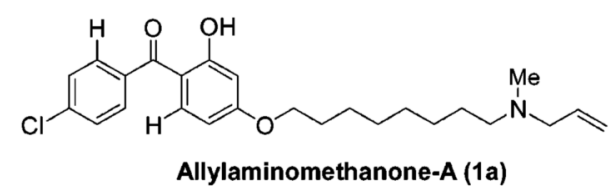

Allylaminomethanone-A (1a)

or $\mathrm{H}$

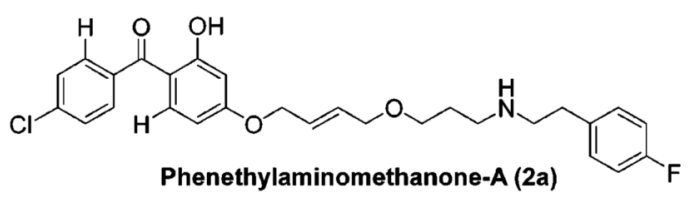

Scheme 1.

Generation of a Library of Molecules in Solution ${ }^{10}$,

${ }^{a}$ Reagents and conditions: (a) $\mathrm{AlCl}_{3}, \mathrm{PhNO}_{2}$ (75-90\%); (b) (i) $48 \% \mathrm{HBr}, \mathrm{AcOH}$ (90\%); (ii) 1,5-dibromopentane or 1,6-dibromohexane or 1,7-dibromoheptane or 1,8-dibromooctane, $\mathrm{K}_{2} \mathrm{CO}_{3}$, DMF (for 1) (80-95\%); 1,4-dibromobutane, $\mathrm{K}_{2} \mathrm{CO}_{3}$, DMF; 1,3-propanediol, NaH, DMF; $\mathrm{CBr}_{4}, \mathrm{PPh}_{3}, \mathrm{CH}_{2} \mathrm{Cl}_{2}$ (for 2) (65\%); 1,4-dibromobutene, $\mathrm{K}_{2} \mathrm{CO}_{3}$, DMF; 1,3-propanediol, $\mathrm{NaH}, \mathrm{DMF} ; \mathrm{CBr}_{4}, \mathrm{PPh}_{3}, \mathrm{CH}_{2} \mathrm{Cl}_{2}$ (for 3) (65\%); 1,4-dibromobutyne, $\mathrm{K}_{2} \mathrm{CO}_{3}$, DMF; 1,3propanediol, $\mathrm{NaH}$, DMF; $\mathrm{CBr}_{4}, \mathrm{PPh}_{3}, \mathrm{zCH}_{2} \mathrm{Cl}_{2}$ (for 4) $\left(65 \%\right.$ ); (iii) $\mathrm{R}_{5}$ (primary or secondary amines or hydrazines), $\mathrm{NaHCO}_{3}, \mathrm{DMF}$ (50-98\%); (iv) TFA, $\mathrm{CH}_{2} \mathrm{Cl}_{2}$ (for Boc-protected $\mathrm{R}_{5}$ ) $(100 \%)$. 


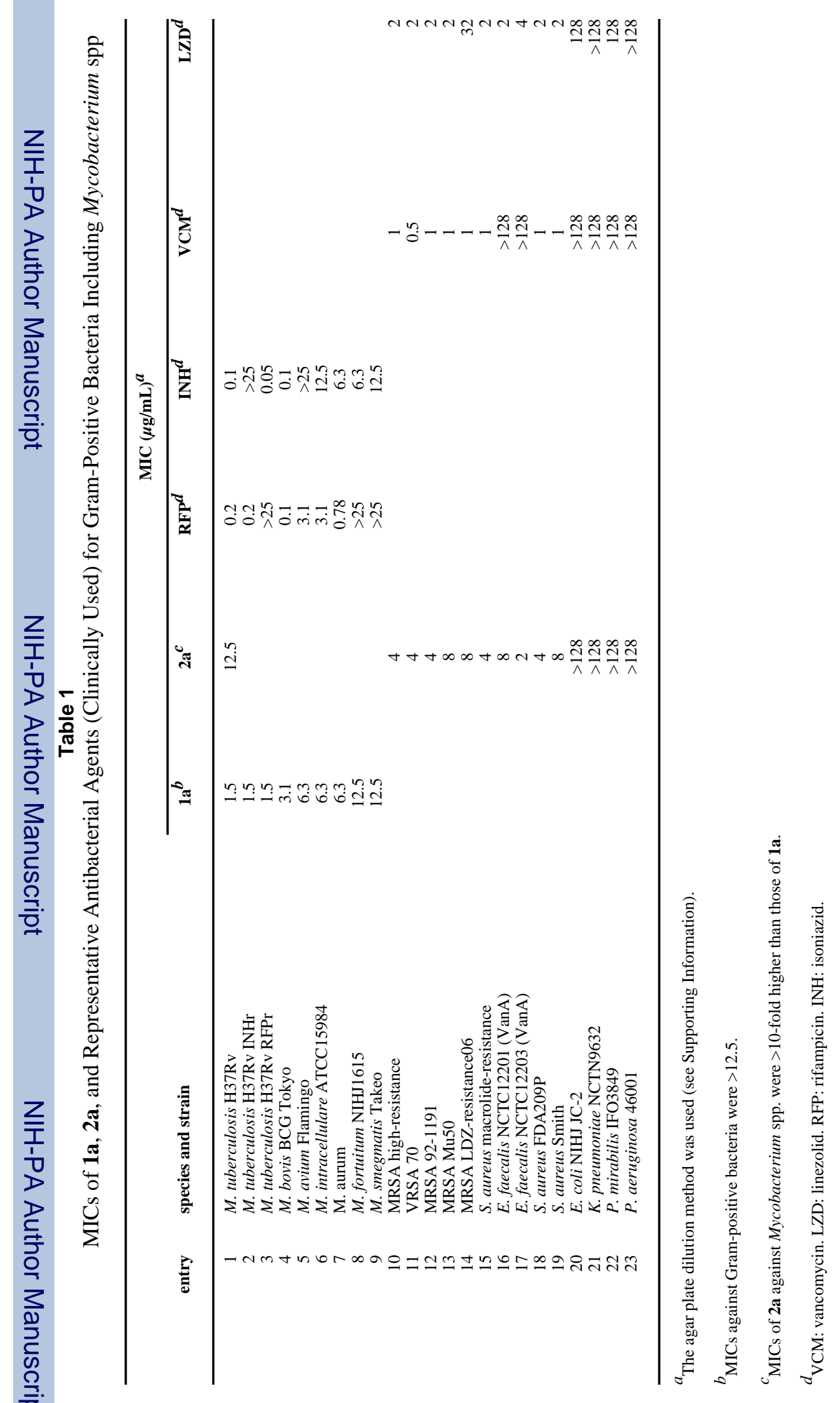

J Med Chem. Author manuscript; available in PMC 2008 December 1. 